\title{
ToP-DNJ, a Selective Inhibitor of Endoplasmic Reticulum $\alpha$-Glucosidase II Exhibiting Antiflaviviral Activity
}

\author{
J. L. Kiappes, ${ }^{\dagger}$ Michelle L. Hill, ${ }^{\dagger}$ Dominic S. Alonzi, ${ }^{\dagger}$ Joanna L. Miller, ${ }^{\dagger}$ Ren Iwaki, ${ }^{\ddagger}$ Andrew C. Sayce, \\ Alessandro T. Caputo, ${ }^{\dagger}$ Atsushi Kato, ${ }^{\ddagger}$ and Nicole Zitzmann* ${ }^{*}+$ (이 \\ ${ }^{\dagger}$ Department of Biochemistry, University of Oxford, South Parks Road, Oxford OX1 3QU, U.K. \\ ${ }^{\ddagger}$ Department of Hospital Pharmacy, University of Toyama, 2630 Sugitani, Toyama 930-0194, Japan
}

\section{Supporting Information}

ABSTRACT: Iminosugars have therapeutic potential against a range of diseases, due to their efficacy as glycosidase inhibitors. A major challenge in the development of iminosugar drugs lies in making a compound that is selective for the glycosidase associated with a given disease. We report the synthesis of ToP-DNJ, an antiviral iminosugar-tocopherol conjugate. Tocopherol was incorporated into the design of the iminosugar in order to direct the drug to the liver and immune cells, specific tissues of interest for antiviral therapy. ToP-DNJ inhibits ER $\alpha$-glucosidase II at low micromolar concentrations and selectively accumulates in the liver in vivo. In cellular assays, the drug showed efficacy exclusively in immune cells of the myeloid lineage. Taken together, these data demonstrate that inclusion of a native metabolite into an iminosugar provides selectivity with respect to target enzyme, target cell, and target tissue.
Tminosugars are characterized by their nitrogen-containing heterocycles and ability to mimic monosaccharides. They have been investigated for their therapeutic potential against a variety of diseases including diabetes, genetic sphingolipidoses, and viral infections, with several iminosugar drugs in clinical use and clinical trials. ${ }^{1-11}$ A major challenge for the development of these molecules is that the ubiquity of sugars and sugar processing enzymes throughout the body, which allows iminosugars to be therapeutic with respect to so many diseases, also leads to a variety of side effects. ${ }^{2}$ We perceived two ways of improving selectivity: (i) developing a drug that has activity against only the target enzyme and (ii) directing the drug preferentially to target cells and tissues.

Our interests lie in the application of iminosugars as antivirals, particularly for the treatment of hepatitis $C$ virus $(\mathrm{HCV})$ and dengue virus (DENV). The therapeutic effect is theorized to occur via inhibition of the endoplasmic reticulum $\alpha$-glucosidases I and II (GluI and GluII). 4,6,10,11 These two enzymes are antiviral targets due to their key role in regulating entry into the endoplasmic reticulum quality control (ERQC) pathway. As $\mathrm{N}$-linked glycoproteins are being translocated into the ER, a 14-sugar oligosaccharide is transferred en bloc onto the nascent polypeptide. The first two steps of glycan processing are carried out by GluI and GluII, sequentially removing the two terminal glucose residues of the oligosaccharide (Figure 1A). The resulting monoglucosylated glycan serves as a "tag" for recognition by calnexin and calreticulin, which mediate interactions with host chaperones that make up ERQC to allow proper glycoprotein folding. GluII acts a second time to remove the final glucose residue, which means that the protein can no longer interact with calnexin and calreticulin. Enveloped viruses that contain $\mathrm{N}$-glycosylated envelope and nonstructural proteins rely on this host glycoprotein folding process. Inhibition of GluI and GluII by iminosugars keeps the protein-linked $\mathrm{N}$-glycans from being processed to the monoglucosylated stage, preventing these proteins from interacting with ERQC, which in turn can lead to misfolding. Without properly folded viral glycoproteins, morphogenesis and infectivity of the virus are compromised. Iminosugars are effective against a host of viruses including HCV, DENV, HIV, hepatitis B virus, influenza, and others. 6,12

Because limited high-resolution structural information was available for these enzymes when the project began, a structurebased inhibitor design approach was intractable. Instead, we conceived that cell or tissue targeting could be achieved by conjugation of an iminosugar to a metabolite, thus directing the attached iminosugar according to the metabolite's own distribution. Previously, iminosugars have been successfully targeted to the ER via encapsulation into liposomes; ${ }^{13}$ however, degradation of liposomes "on the shelf" made this methodology undesirable for long-term storage or treatment. In contrast, by uniting the pharmacophore and targeting moieties into a single molecule, the stability is defined by that of the molecule itself rather than a vehicle.

Received: October 7, 2017

Accepted: November 21, 2017

Published: November 21, 2017 


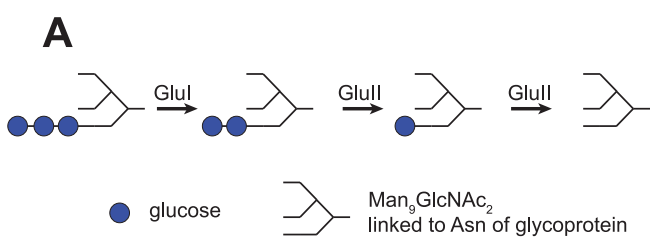

B

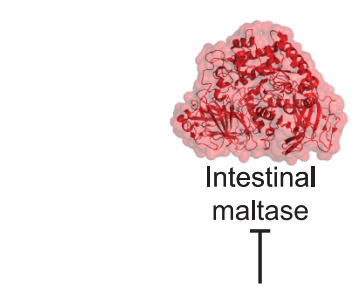<smiles>OCC1NC[C@@H](O)[C@H](O)[C@H]1O</smiles><smiles>CCCCN1C[C@H](O)[C@H](O)[C@H](O)[C@H]1CO</smiles>

1

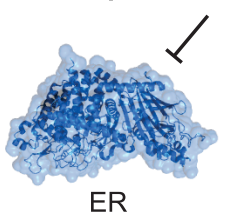

glucosidase I<smiles>Cc1c(C)c2c(c(C)c1O)CC[C@@](C)(CCC[C@@H](C)CCC[C@H](C)CCCC(C)C)O2</smiles>

3

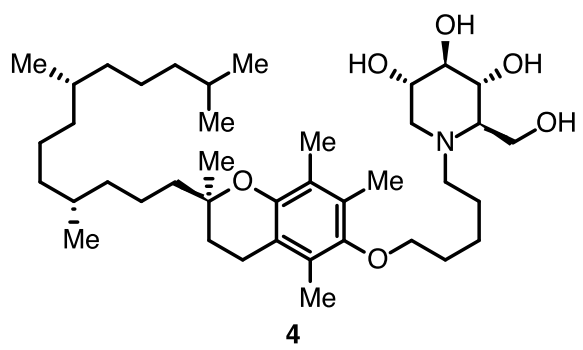

Figure 1. Enzyme targets and structures of iminosugars. (A) Trimming of the $N$-glycan by ER $\alpha$-glucosidases I and II (GluI and GluII). (B) D-1-Deoxynojirimycin 1 and N-butyl-D-1-deoxynojirimycin 2 inhibit the ER-resident enzymes GluI (PDB ID 4J5T), GluII (PDB ID 5F0E), and intestinal glucosidases (e.g., maltase/glucoamylase, PDB ID 3TOP), which, like GluII, are members of glycoside hydrolase family 31. (C) D-(+)- $\alpha$-tocopherol 3 and ToP-DNJ 4.

We selected D-1-deoxynojirimycin (DNJ) 1 (Figure 1B) as the iminosugar component due to the broad-spectrum antiviral activity of $\mathbf{1}$ and its $\mathrm{N}$-alkyl derivatives (e.g., $\mathrm{N}$-butyl-DNJ 2). ${ }^{6}$ $\mathrm{D}-\alpha$-Tocopherol 3, a form of vitamin E (Figure 1C), was selected as the metabolite to be conjugated to the iminosugar as it is nontoxic. ${ }^{14}$ As 3 accumulates in two places desirable for antiviral therapy, we hoped it could serve as a tissue-targeting moiety. After being absorbed in the gut, 3 is packaged in the liver, the target organ of $\mathrm{HCV}$ and a potential reservoir for DENV. ${ }^{15}$ Coupling 3 to siRNA directs the conjugate to the liver in vivo, ${ }^{16}$ though this has never been demonstrated for a small molecule conjugate nor via oral administration. Compound 3 also accumulates in the membranes of immune cells, ${ }^{17}$ one of the target cell types of DENV. So that both the DNJ and tocopherol moieties could be recognized independently by biological partners, a 5-carbon chain was employed as a flexible linker, resulting in the target structure $5^{\prime}$-tocopheroxypentyl-DNJ (ToP-DNJ, 4).

A convergent route (Scheme 1) was designed with eventual exploration of structure-activity relationships (SAR) in mind, with straightforward replacement of any of the 3 subunits (linker, iminosugar, or metabolite) possible to allow optimization of each component. Desymmetrization of 1,5pentanediol provided linker compound 5 (Supplemental Scheme 1). ${ }^{18-20}$ Deprotonation of tocopherol 3 (NaH, DMF, $0{ }^{\circ} \mathrm{C}$ ) yielded a nucleophilic phenolate anion that attacked alkyl tosylate 5 to give tocopheryl ether $\mathbf{6}$ ( $86 \%$ yield). With the metabolite attached, the other end of the linker could be unmasked $\left(p-\mathrm{TsOH}, \mathrm{H}_{2} \mathrm{O}\right)$ to reveal aldehyde 7 (99\% yield). Due to the lipophilicity of the tocopherol moiety, 7 was coupled to tetra-O-acetyl DNJ $8^{21}$ rather than free DNJ 1 , so that the two reactants could be dissolved in a single phase. The reductive amination $\left(\mathrm{Na}(\mathrm{AcO})_{3} \mathrm{BH}\right.$, cat. $\left.\mathrm{HOAc}, \mathrm{Na}_{2} \mathrm{SO}_{4}\right)$ proceeded smoothly to give per-acetylated ToP-DNJ 9 (53\% yield), and subsequent removal of the acetyl protecting groups $(\mathrm{NaOMe}, \mathrm{MeOH})$ provided 4 (71\% yield). Attempts were made to couple 7 directly with DNJ 1 , but the lack of mutual solubility resulted in lower yields of 4 .

With 4 in hand, we examined the biological activities of the lead compound as a proof of concept. To begin characterization of 4 , we addressed whether the addition of the large tocopherol moiety abolished the ability of the iminosugar to inhibit glucosidases. In vitro inhibition studies of isolated glucosidases $^{22}$ were carried out (Supplemental Table 1 and Supplemental Figure 1). In addition to the targeted enzymes GluI and GluII, the effects of 4 on $\alpha$-glucosidases (intestinal maltase, intestinal isomaltase, intestinal sucrase, and lysosomal glucosidase) and on a $\beta$-glucosidase (intestinal cellobiase) were analyzed, as off-target inhibition of these can cause undesirable gastrointestinal side effects. ${ }^{2}$ The activity of $\mathbf{4}$ was compared to that of the parent compound $\mathbf{1}$ and the clinically approved drug $2,{ }^{10}$ both of which inhibit all of the tested $\alpha$-glucosidases. Surprisingly, 4 showed a remarkable selectivity for GluII. It has a comparable $\mathrm{IC}_{50}$ (concentration that gives $50 \%$ inhibition) to 1 and 2 with regard to GluII ( $\mathrm{IC}_{50}$ values $9.0,13$, and $16 \mu \mathrm{M}$ for 4,2 , and 1, respectively) but shows less than $50 \%$ inhibition of the other tested enzymes at the maximum tested concentration of $50 \mu \mathrm{M}$. This selectivity for GluII has not been reported for any other DNJ compound and represents a huge step toward developing an antiviral of this class of iminosugars (which requires ER $\alpha$-glucosidase inhibition) without associated gastrointestinal side effects (due to inhibition of the intestinal glucosidases). GluII and the intestinal $\alpha$-glucosidases are all members of glycoside hydrolase family 31 ; it is therefore difficult to suggest a molecular explanation for the selectivity of 4 toward the ER-resident enzyme. Preliminary comparison of the active site of recently reported crystal structures of GluII $^{23,24}$ and that of intestinal maltase and glucoamylase $e^{25,26}$ does not reveal the molecular origin of selectivity. 
Scheme 1. Synthesis of ToP-DNJ 4<smiles></smiles>

3

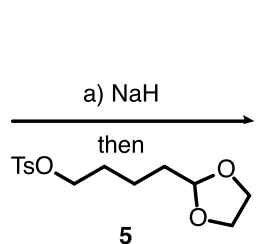

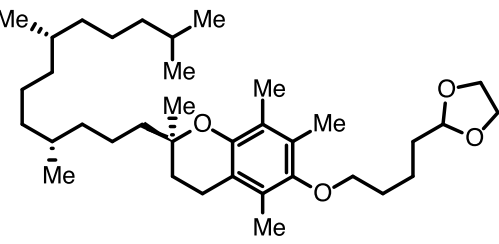

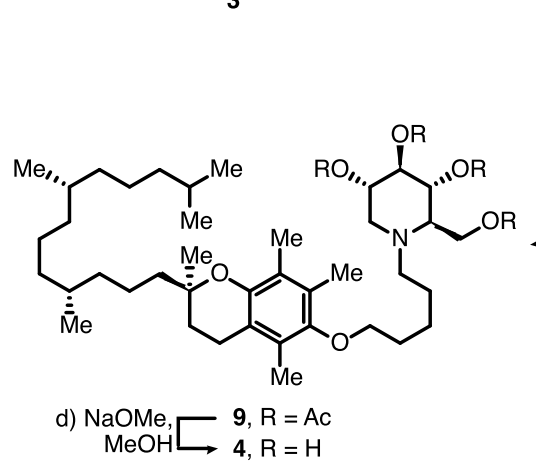

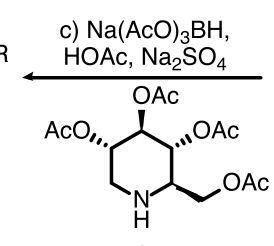

8

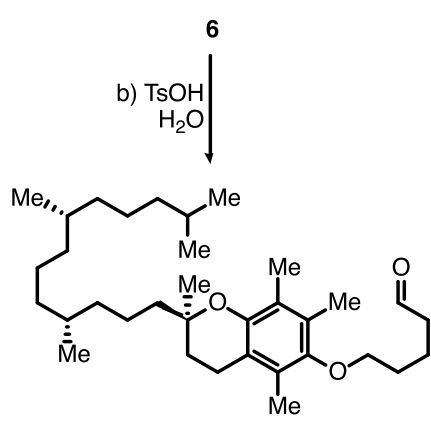

7
After demonstrating inhibition of GluII in vitro, 4 was next evaluated for its ability to disrupt activity of the same enzyme in the host cells in which we routinely evaluate compounds for inhibition of HCV and DENV: primary human monocytederived macrophages (MDM $\Phi$, for DENV) and the human hepatoma Huh7.5 cell line (for HCV and DENV). Inhibition of GluI and GluII in cell culture is measured by assaying the levels of free oligosaccharides (FOS). ${ }^{27}$ In the absence of ER $\alpha$ glucosidase inhibition, the only glucosylated FOS observed are low levels of $\mathrm{Glc}_{1} \mathrm{Man}_{5} \mathrm{GlcNAc}_{1}$. In general, when cells are treated with 2, mono-, di-, and triglucosylated species can be observed indicating that both GluI and GluII are inhibited. ${ }^{27}$ Accumulation of mono- and diglucosylated species $\left(\mathrm{Glc}_{1} \mathrm{Man}_{4} \mathrm{GlcNAc}_{1}\right.$ and $\mathrm{Glc}_{2} \mathrm{Man}_{4} \mathrm{GlcNAc}_{1}$, respectively) result from inhibition of GluII, while triglucosylated glycans $\left(\mathrm{Glc}_{3} \mathrm{Man}_{5} \mathrm{GlcNAc}_{1}\right)$ serve as a biomarker for inhibition of GluI. In contrast to 2, 4 demonstrated selectivity in terms of both enzyme and cell type. Glucosylated FOS were observed in naive MDMФ (Figure 2A) but not in naive Huh7.5 cells. Only monoglucosylated FOS accumulated in 4-treated MDM $\Phi$, while mono- and triglucosylated FOS were observed in cells similarly treated with 2 . This further confirms the results of in vitro enzyme assays that $\mathbf{4}$ inhibits only GluII, while $\mathbf{2}$ inhibits both ER-resident glucosidases. In the Huh7.5 cells, no glucosylated FOS were observed, indicating that 4 inhibited neither GluI nor GluII in these cells, while 2 inhibits both enzymes in the same cells (Supplemental Figure 2A).

To examine the cell-type selectivity more thoroughly, additional human cell lines were treated with $\mathbf{4}$ and analyzed for FOS. Glu $\mathrm{Man}_{4} \mathrm{GlcNAc}_{1}$ was detected in HL60 (promyelocytic) cells (Supplemtnal Figure 2B) but not in Jurkat ( $\mathrm{T}$ lymphocyte, Supplemental Figure 2C) nor Raji (B lymphocyte, Supplemental Figure 2D) cells. The fact that FOS were observed only in the MDM $\Phi$ and HL60 cells indicates that 4 affects only myeloid lineage immune cells. The GluII enzyme is the same in all human cells, suggesting that $\mathbf{4}$ is more effectively absorbed by myeloid lineage cell types than others. This is consistent with our initial hypothesis that the biological uptake of 4 would be influenced by the patterns of the constituent 3 , as immune cells are known to have increased amounts of $\mathbf{3}$ in their membranes, suggesting that they likely have mechanisms for
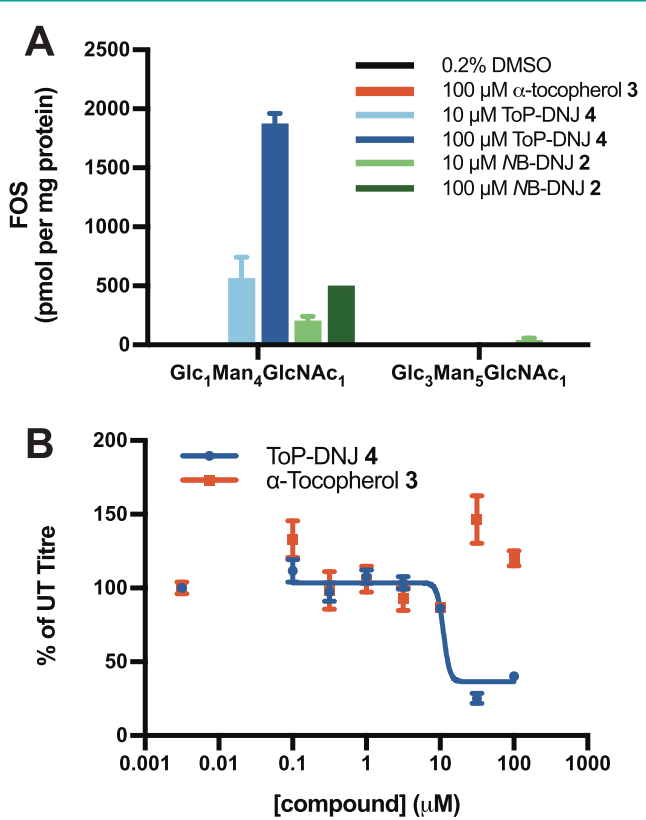

Figure 2. Effects of ToP-DNJ 4 treatment in monocyte-derived macrophages (MDMФ). (A) Protein-normalized free oligosaccharide levels of naive MDMФ (1 representative donor). The bar represents the mean; error bars show one standard deviation. (B) Infectious virus titer produced by dengue-infected MDM $\Phi$ (7 donors) under ToPDNJ 4 or $\alpha$-tocopherol 3 treatment. Compound 4 has an $\mathrm{IC}_{50}$ of 12.7 $\mu \mathrm{M}$, while 3 showed no antiviral effect. The data points represent the mean; error bars show standard error of the mean.

enhanced uptake of this moiety. This opens up an exciting new strategy for targeting specific host cells, thereby reducing offtarget effects typical of iminosugars.

The FOS produced under treatment with $\mathbf{4}$ in both the primary MDM $\Phi$ and HL60 cells included only monoglucosylated species, indicating inhibition of the second reaction catalyzed by GluII. However, no diglucosylated species were detected, raising the question whether 4 inhibits only one of the reactions catalyzed by GluII. In an effort to address this question, we measured the inhibition of GluII in vitro using a fluorescently labeled analogue of a native glycan substrate 
$\left(\mathrm{Glc}_{2} \mathrm{Man}_{7} \mathrm{GlcNAc}_{1}\right)$, rather than $\alpha$-p-nitrophenylglucoside. Compound 4 inhibited both reactions of GluII, with a more potent influence on the first reaction catalyzed by the enzyme (IC $_{50}$ of $14 \mu \mathrm{M}$ for the conversion of diglucosylated to monoglucosylated versus $56 \mu \mathrm{M}$ for the conversion of monoglucosylated to nonglucosylated glycan). This suggests that the lack of diglucosylated FOS in the primary MDM $\Phi$ and HL60 experiments is due to the kinetics of cellular glycan processing, rather than a property of the inhibitor 4 .

Given the more selective inhibition profile of 4 , it remained to be determined whether it retained the antiviral activity observed for other members of the iminosugar class. Compound 4 was antiviral with respect to DENV in primary MDM $\Phi$ cells (Figure 2B), in which GluII is inhibited as shown by FOS assay, but in Huh7.5 cells, in which GluII is not inhibited, neither an anti-DENV nor anti-HCV effect was observed (Supplemental Figure 3). This is consistent with the theory that inhibition of GluII is key to the antiviral effect. The $\mathrm{IC}_{50}$ of $4(12.7 \mu \mathrm{M})$ for DENV inhibition in MDM $\Phi$ cells $(7$ donors) is similar to that determined for $2(6.00 \mu \mathrm{M})^{28}$ in the same system. Notably, 4 has an antiviral effect in MDM $\Phi$ cells in the absence of any GluI inhibition activity, suggesting that GluII inhibition alone is sufficient for an anti-DENV effect.

The in vitro and whole cell assays characterized the targeted effects of the conjugated tocopherol on selectivity for specific glucosidases and cell types. However, to see whether it influenced the distribution of the iminosugar in different tissues, biodistribution studies were carried out in 4-treated mice, with investigations of oral and intravenous administration routes. In both cases, 4 was detected in the highest amounts in the liver (Figure 3A, intravenous (IV) data; orally administered (per os, PO), Supplemental Figure 4), whereas 2 is found in the highest amounts in the kidneys and bladder as it is renally

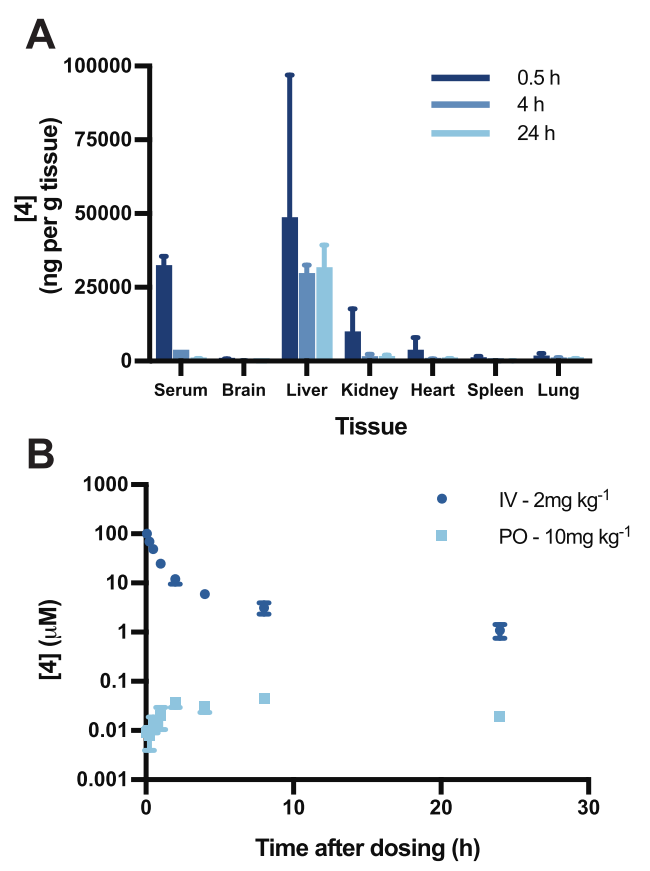

Figure 3. In vivo studies of ToP-DNJ 4 in $\mathrm{BALB} / \mathrm{c}$ mice. (A) The concentration of 4 in all organs after intravenous (IV) administration. (B) Serum concentration of $\mathbf{4}$ over time (IV and per os, PO). On both graphs, the mean of 3 animals is shown; error bars show one standard deviation. excreted. ${ }^{29,30}$ The amount of 4 present in the liver did not decrease between the 4 and $24 \mathrm{~h}$ time points. In contrast, simple alkylated iminosugars are eliminated from the liver by more than $80 \%$ during the same time period. ${ }^{29}$ In addition, the plasma terminal half-life of 4 was $8.79 \mathrm{~h}$ (Figure 3B), compared to $5 \mathrm{~h}$ for $2 .^{30}$ The increase in half-life both in plasma and in the liver means that a single dose will have longer term therapeutic effects than previously investigated iminosugars. Compound 4 has poor oral bioavailability, achieving a maximum blood plasma concentration of $46 \mathrm{nM}$ after $8 \mathrm{~h}$ (Figure 3B). However, the absorption of 3 depends on coconsumed nutrients. Consumption of 3 with a lipid-rich meal leads to 10-fold higher plasma levels. ${ }^{31}$ Compound 4 might similarly require other hydrophobic molecules for efficient absorption after oral administration. Despite this limitation with regard to oral absorption, the high liver levels of $\mathbf{4}$ demonstrate that tissuetargeting of small molecules can be accomplished by the incorporation of the tocopherol moiety, regardless of administration route.

In conclusion, we prepared DNJ-tocopherol conjugate 4, the first reported DNJ derivative to be a selective inhibitor of GluII. This selectivity was demonstrated both for isolated enzymes and in a whole cell system. By eliminating inhibition of the intestinal glucosidases, 4 could overcome the side effects both in antiviral iminosugar clinical candidates and in FDAapproved 2. With a selective GluII inhibitor in hand, we discovered that GluI inhibition is not obligate for antiviral activity. Given the cell type specificity of $\mathbf{4}$ and the correlation of FOS and antiviral effect, it was substantiated that ER $\alpha$ glucosidase inhibition, and not an alternative effect of DNJ compounds, is the mechanism of action for anti-DENV activity. Furthermore, incorporation of vitamin $\mathrm{E}$ into the iminosugar bestowed improved plasma and liver half-lives, as well as cell type dependent activity, which could be exploited for tailormaking drugs for host cells of specific viruses, leaving other cell types less affected. While we continue to study the properties of 4, investigations are also proceeding to establish SAR for each of these novel iminosugar capabilities, as well as work on further iminosugar-metabolite conjugates.

\section{METHODS}

Chemistry. Methods for the synthesis of ToP-DNJ 4, compound characterization, and spectra are described in detail in the Supporting Information.

Biological Assays. Methods for in vitro inhibition of isolated enzymes can be found in the Supporting Information. Methods used for evaluating the cellular inhibition of the ER glucosidases, as well as inhibition of HCV and DENV, are detailed in the Supporting Information, which also describes the procedures used in the biodistribution studies.

\section{ASSOCIATED CONTENT}

\section{Supporting Information}

The Supporting Information is available free of charge on the ACS Publications website at DOI: 10.1021/acschembio. 7 b00870.

Scheme 1 with detailed reagents and conditions, scheme for synthesis of pentyl linker, table of inhibition of isolated enzymes in vitro, figures of in vitro inhibition of GluII by 4, free oligosaccharide analysis of cell lines treated with $\mathbf{4}$, antiviral activity of $\mathbf{4}$ in human hepatoma Huh7.5 cell line, and mouse biodistribution of orally- 
administered 4, in-depth experimental procedures, and NMR spectra (PDF)

\section{AUTHOR INFORMATION}

\section{Corresponding Author}

*E-mail: nicole.zitzmann@bioch.ox.ac.uk.

ORCID $\odot$

J. L. Kiappes: 0000-0001-6697-6776

Nicole Zitzmann: 0000-0003-1969-4949

\section{Notes}

The authors declare no competing financial interest.

\section{ACKNOWLEDGMENTS}

Financial support for this work was provided by the Oxford Glycobiology Endowment, Unither Virology LLC, a LernerFink Fellowship in Medicinal Chemistry (to J.L.K.), a Wellcome Trust predoctoral fellowship (to A.T.C., 097300/ $\mathrm{Z} / 11 / \mathrm{Z}$ ), and a Grant-in-Aid for Scientific Research (C) from the Japanese Society for the Promotion of Science (to A.K. JSPS KAKENHI Grant Number JP17K08362). The authors thank R. Dwek and K. Scott for useful discussions and M. Wormald and A. Kumar for NMR spectroscopy and mass spectrometry assistance, respectively.

\section{REFERENCES}

(1) Mehta, A., Zitzmann, N., Rudd, P. M., Block, T. M., and Dwek, R. A. (1998) Alpha-glucosidase inhibitors as potential broad based antiviral agents. FEBS Lett. 430, 17-22.

(2) Butters, T. D., Dwek, R. A., and Platt, F. M. (2005) Imino sugar inhibitors for treating the lysosomal glycosphingolipidoses. Glycobiology $15,43 \mathrm{R}-52 \mathrm{R}$.

(3) Martin, O. (2007) Les Iminosucres: applications thérapeutiques actuelles et futures. Ann. Pharm. Fr. 65, 5-13.

(4) Sayce, A. C., Miller, J. L., and Zitzmann, N. (2010) Targeting a host process as an antiviral approach against dengue virus. Trends Microbiol. 18, 323-330.

(5) Nash, R. J., Kato, A., Yu, C.-Y., and Fleet, G. W. (2011) Iminosugars as therapeutic agents: recent advances and promising trends. Future Med. Chem. 3, 1513-1521.

(6) Chang, J., Block, T. M., and Guo, J.-T. (2013) Antiviral therapies targeting host ER alpha-glucosidases: Current status and future directions. Antiviral Res. 99, 251-260.

(7) Dalziel, M., Crispin, M., Scanlan, C. N., Zitzmann, N., and Dwek, R. A. (2014) Emerging principles for the therapeutic exploitation of glycosylation. Science (Washington, DC, U. S.) 343, 1235681.

(8) Low, J. G., Sung, C., Wijaya, L., Wei, Y., Rathore, A. P. S., Watanabe, S., Tan, B. H., Toh, L., Chua, L. T., Hou, Y., Chow, A., Howe, S., Chan, W. K., Tan, K. H., Chung, J. S., Cherng, B. P., Lye, D. C., Tambayah, P. A., Ng, L. C., Connolly, J., Hibberd, M. L., Leo, Y. S., Cheung, Y. B., Ooi, E. E., and Vasudevan, S. G. (2014) Efficacy and safety of celgosivir in patients with dengue fever (CELADEN): a phase $1 \mathrm{~b}$, randomised, double-blind, placebo-controlled, proof-of-concept trial. Lancet Infect. Dis. 14, 706-715.

(9) Watanabe, S., Chan, K. W.-K., Dow, G., Ooi, E. E., Low, J. G., and Vasudevan, S. G. (2016) Optimizing celgosivir therapy in mouse models of dengue virus infection of serotypes 1 and 2: The search for a window for potential therapeutic efficacy. Antiviral Res. 127, 10-19.

(10) Sayce, A. C., Alonzi, D. S., Killingbeck, S. S., Tyrrell, B. E., Hill, M. L., Caputo, A. T., Iwaki, R., Kinami, K., Ide, D., Kiappes, J. L., Beatty, P. R., Kato, A., Harris, E., Dwek, R. A., Miller, J. L., and Zitzmann, N. (2016) Iminosugars inhibit dengue virus production via inhibition of ER alpha-glucosidases-not glycolipid processing enzymes. PLoS Neglected Trop. Dis. 10, e0004524.

(11) Warfield, K. L., Plummer, E. M., Sayce, A. C., Alonzi, D. S., Tang, W., Tyrrell, B. E., Hill, M. L., Caputo, A. T., Killingbeck, S. S.,
Beatty, P. R., Harris, E., Iwaki, R., Kinami, K., Ide, D., Kiappes, J. L., Kato, A., Buck, M. D., King, K., Eddy, W., Khaliq, M., Sampath, A., Treston, A. M., Dwek, R. A., Enterlein, S. G., Miller, J. L., Zitzmann, N., Ramstedt, U., and Shresta, S. (2016) Inhibition of endoplasmic reticulum glucosidases is required for in vitro and in vivo dengue antiviral activity by the iminosugar UV-4. Antiviral Res. 129, 93-98.

(12) Alonzi, D. S., Scott, K. A., Dwek, R. A., and Zitzmann, N. (2017) Iminosugar antivirals: the therapeutic sweet spot. Biochem. Soc. Trans. 45, 571-582.

(13) Pollock, S., Antrobus, R., Newton, L., Kampa, B., Rossa, J., Latham, S., Nichita, N. B., Dwek, R. A., and Zitzmann, N. (2010) Uptake and trafficking of liposomes to the endoplasmic reticulum. FASEB J. 24, 1866-1878.

(14) Kappus, H., and Diplock, A. T. (1992) Tolerance and safety of vitamin E: a toxicological position report. Free Radical Biol. Med. 13, $55-74$.

(15) Balsitis, S. J., Coloma, J., Castro, G., Alava, A., Flores, D., McKerrow, J. H., Beatty, P. R., and Harris, E. (2009) Tropism of dengue virus in mice and humans defined by viral nonstructural protein 3-specific immunostaining. Am. J. Trop. Med. Hyg. 80, 416424.

(16) Nishina, K., Unno, T., Uno, Y., Kubodera, T., Kanouchi, T., Mizusawa, H., and Yokota, T. (2008) Efficient In vivo delivery of siRNA to the liver by conjugation of $\alpha$-Tocopherol. Mol. Ther. 16, 734-740.

(17) Wang, X., and Quinn, P. J. (2000) The location and function of vitamin $\mathrm{E}$ in membranes (Review). Mol. Membr. Biol. 17, 143-156.

(18) Bouzide, A., and Sauvé, G. (1997) Highly selective silver (I) oxide mediated monoprotection of symmetrical diols. Tetrahedron Lett. $38,5945-5948$

(19) Davison, E. C., Fox, M. E., Holmes, A. B., Roughley, S. D., Smith, C. J., Williams, G. M., Davies, J. E., Raithby, P. R., Adams, J. P., Forbes, I. T., Press, N. J., and Thompson, M. J. (2002) Nitrone dipolar cycloaddition routes to piperidines and indolizidines. Part 9. Formal synthesis of (-)-pinidine and total synthesis of (-)-histrionicotoxin, $(+)$-histrionicotoxin and (-)-histrionicotoxin 235A. J. Chem. Soc., Perkin Trans. 1, 1494-1514.

(20) Wennekes, T., van den Berg, R. J. B. H. N., Donker, W., van der Marel, G. A., Strijland, A., Aerts, J. M. F. G., and Overkleeft, H. S. (2007) Development of adamantan-1-yl-methoxy-functionalized 1deoxynojirimycin derivatives as selective inhibitors of glucosylceramide metabolism in man. J. Org. Chem. 72, 1088-1097.

(21) Heuckendorff, M., Pedersen, C. M., and Bols, M. (2010) Quantifying Electronic Effects of Common Carbohydrate Protecting Groups in a Piperidine Model System. Chem. - Eur. J. 16, 1398213994.

(22) Asano, N., Nishida, M., Kato, A., Kizu, H., Matsui, K., Shimada, Y., Itoh, T., Baba, M., Watson, A. A., Nash, R. J., Lilley, P. M., Watkin, D. J., and Fleet, G. W. J. (1998) Homonojirimycin isomers and Nalkylated homonojirimycins: structural and conformational basis of inhibition of glycosidases. J. Med. Chem. 41, 2565-2571.

(23) Satoh, T., Toshimori, T., Yan, G., Yamaguchi, T., and Kato, K. (2016) Structural basis for two-step glucose trimming by glucosidase II involved in ER glycoprotein quality control. Sci. Rep. 6, 20575.

(24) Caputo, A. T., Alonzi, D. S., Marti, L., Reca, I. B., Kiappes, J. L., Struwe, W. B., Cross, A., Basu, S., Lowe, E. D., Darlot, B., Santino, A., Roversi, P., and Zitzmann, N. (2016) Structures of mammalian ER $\alpha$ glucosidase II capture the binding modes of broad-spectrum iminosugar antivirals. Proc. Natl. Acad. Sci. U. S. A. 113, E4630-8.

(25) Sim, L., Willemsma, C., Mohan, S., Naim, H. Y., Pinto, B. M., and Rose, D. R. (2010) Structural basis for substrate selectivity in human maltase-glucoamylase and sucrase-isomaltase $\mathrm{N}$-terminal domains. J. Biol. Chem. 285, 17763-17770.

(26) Ren, L., Qin, X., Cao, X., Wang, L., Bai, F., Bai, G., and Shen, Y. (2011) Structural insight into substrate specificity of human intestinal maltase-glucoamylase. Protein Cell 2, 827-836.

(27) Alonzi, D. S., Neville, D. C. A., Lachmann, R. H., Dwek, R. A., and Butters, T. D. (2008) Glucosylated free oligosaccharides are 
biomarkers of endoplasmic- reticulum alpha-glucosidase inhibition. Biochem. J. 409, 571-580.

(28) Miller, J. L., Lachica, R., Sayce, A. C., Williams, J. P., Bapat, M., Dwek, R., Beatty, P. R., Harris, E., and Zitzmann, N. (2012) Liposomemediated delivery of iminosugars enhances efficacy against dengue virus in vivo. Antimicrob. Agents Chemother. 56, 6379-6386.

(29) Mellor, H. R., Nolan, J., Pickering, L., Wormald, M. R., Platt, F. M., Dwek, R. A., Fleet, G. W. J., and Butters, T. D. (2002) Preparation, biochemical characterization and biological properties of radiolabelled $N$-alkylated deoxynojirimycins. Biochem. J. 366, 225-233.

(30) Treiber, A., Morand, O., and Clozel, M. (2007) The pharmacokinetics and tissue distribution of the glucosylceramide synthase inhibitor miglustat in the rat. Xenobiotica 37, 298-314.

(31) Jeanes, Y. M., Hall, W. L., Ellard, S., Lee, E., and Lodge, J. K. (2004) The absorption of vitamin $\mathrm{E}$ is influenced by the amount of fat in a meal and the food matrix. Br. J. Nutr. 92, 575-579. 